Intersections

Canadian Journal of Music

Revue canadienne de musique

\title{
William Caplin Responds
}

\section{William Caplin}

Volume 31, numéro 1, 2010

Contemplating Caplin

URI : https://id.erudit.org/iderudit/1009286ar

DOI : https://doi.org/10.7202/1009286ar

Aller au sommaire du numéro

Éditeur(s)

Canadian University Music Society / Société de musique des universités

canadiennes

\section{ISSN}

1911-0146 (imprimé)

1918-512X (numérique)

Découvrir la revue

Citer cet article

Caplin, W. (2010). William Caplin Responds. Intersections, 31(1), 67-76.

https://doi.org/10.7202/1009286ar

All Rights Reserved (c Canadian University Music Society / Société de musique des universités canadiennes, 2012
Ce document est protégé par la loi sur le droit d'auteur. L’utilisation des services d'Érudit (y compris la reproduction) est assujettie à sa politique d'utilisation que vous pouvez consulter en ligne.

https://apropos.erudit.org/fr/usagers/politique-dutilisation/ 


\section{WILLIAM CAPLIN RESPONDS}

I would like to begin by thanking the program committee of the 2010 Conference of the Canadian University Music Society for asking me to respond to the three papers on musical form presented at a session on the "Analysis of Classical-Era Music." I also wish to thank the editors of Intersections for inviting me to publish my comments on the written versions of these papers that now appear in this issue. It is a rare occasion when all of the speakers on a session directly engage one's own research, and I am most gratified to see the creative ways in which my theoretical work has been confronted and advanced.

\section{EDWARD JURKOWSKI}

With his study of Clementi's op. 36 Sonatinas, Edward Jurkowski has convincingly demonstrated that these works-so familiar to most of us from our early musical education-present a greater sophistication of formal organization than previously suspected. Moreover, he has revealed with precision just how Clementi achieved an increasingly complex articulation of expositional structures. Indeed, I fully endorse Ed's fundamental observation that the opening section of these sonatinas progresses from what we would find in the A section of a simple minuet form all the way to a full-fledged sonata-form exposition. Since I have little to add to his overall thesis, let me instead look again at some of his examples, address a number of specific analytical points, and propose some alternative readings, all of which reinforce his general conclusions.

With respect to the Mozart minuet shown in example 1, Ed identifies a clear example of the concept of transition/subordinate-theme fusion that I developed in Classical Form to cover cases where, within a single formal unit, an exposition both modulates to the new key and confirms it with a perfect authentic cadence (PAC). It must be emphasized that the attainment of such a PAC is a necessary, minimal requirement for subordinate theme function. In other words, the presence of this PAC already means that the "sonata clock" (to use a felicitous expression of Hepokoski and Darcy) ${ }^{1}$ has moved beyond the transition and into the time-world of the subordinate theme. Given this central postulate-that a PAC in the new key already expresses subordinate theme function - a corollary proposition holds that a transition cannot end with the new tonic, but must rather conclude on dominant harmony, normally with a half cadence (HC).

Thus, when we turn to Ed's example 2, it would be somewhat more accurate to label the music beginning with the elided cadence at m. 8 as a "second" subordinate theme, inasmuch as the minimal requirement of a "first" subordinate

1 Elements of Sonata Theory, 150. 
theme-a PAC in the new key-is satisfied by the close of the prior phrase, which fuses transition and subordinate theme functions. If this were a regular minuet form, then its A section could have ended at this point. But given that Clementi is referencing sonata form, albeit in a most compressed manner, the need for something more in the way of subordinate theme material is evident. Thus this "second" subordinate theme brings new melodic-motivic ideas within an initiating formal function (a presentation), followed then by a continuation $\Rightarrow$ cadential phrase to give greater rhetorical weight to a second PAC. The appearance of a sentence (mm. 8-15) following a period (mm. 1-8) results in a "looser" formal expression, appropriate to a sonata-form exposition. ${ }^{2}$

A similar situation holds for example 3 where, following a relatively tightknit periodic hybrid (compound basic idea + consequent), a looser sentential unit (mm. 9-14), closing at first with an imperfect authentic cadence (IAC), expresses the function of second subordinate theme. This partial closure with an IAC demands an extension, one that brings the required PAC in m. 20. But the extension is somewhat unusual in relation to the norms exhibited by Haydn, Mozart, and Beethoven. With these composers, the closing of a subordinate theme on an IAC normally results in the repetition of some prior continuational material in order to make another run at the cadence (eventually achieving the requisite $\mathrm{PAC}$ ). The music rarely backs up to the very beginning of the theme. However, Clementi's exposition does just that. Following the cadence at $\mathrm{m} .14$, the music returns to the opening of the subordinate theme, bringing again the full presentation (mm. 15-18) before launching the cadential unit that effects the PAC (mm. 19-20). It is easy to understand why Clementi repeats the entire theme rather than backing up to the continuation, for the original theme lacks most of the characteristics of that function-fragmentation, sequence, and an acceleration of the surface rhythms. In fact, the opening presentation is followed by a simple two-measure cadential idea, the slight harmonic acceleration of which brings the only continuational feature within this compressed sentence.

A further, interesting implication arises from Clementi's procedure. If it is normal after an IAC to back up to prior continuation material, Clementi suggests that the start of the (second) subordinate theme is itself continuational in some respect. Indeed, we can recognize the ongoing sixteenth-note activity throughout this theme as a sign in this direction. This is not to deny that a clear functional initiation is projected by $\mathrm{mm} .9-12$, but in relation to the opening eight-bar hybrid theme, consisting of two four-bar phrases, the onset of the theme at $\mathrm{m}$. 9 could be regarded as a kind of continuation, one that brings fragmentation into two-bar units and faster surface rhythms. (The final codettas even represent a further stage of fragmentation into one-bar segments.) Such a view suggests that the entire exposition consists, in some sense, of a single thematic process, at least as projected by the grouping structure.

2 Within the spectrum of tight-knit vs. loose formal organization, the period theme-type, with its two highly symmetrical phrases, each receiving cadential closure, normally appears more tightly knit than the sentence type, with its more ongoing, developmental qualities (see Classical Form, 8485 , and 269 , fn. 38 ). 
Turning now to example 5 , Clementi's op. 36 , no. 4 , the cadential situation within the subordinate-theme area is perhaps more complex than Ed suggests. He is correct in pointing out that a standard modulating transition would have ended at $\mathrm{m} .17$ with a $\mathrm{HC}$ of the new key and that the "destabilizing dominant seventh harmony" of that bar signals an impending authentic cadence, thus implying that the music has moved forward into subordinate-theme territory. But he then proposes (in note 16) that an implied authentic cadence is "undermined by the rest on beat one" of m. 18. Picking up on this idea, it might be possible to hear an actual evaded cadence, whereby the tonic on the downbeat of that bar is not thought to group with the preceding cadential gesture, but rather with the material that follows. A similar situation could then be said to occur at $\mathrm{m} .23$, where the sense of evaded cadence is even stronger, as a result of the "one more time" technique. ${ }^{3}$ If both cadences ( $\mathrm{mm} .18$ and 23 ) are evaded, then we would need to re-evaluate the overall structure presented here and see a large-scale fusion of transition and subordinate theme functions, thus creating a single thematic unit within mm. 9-28 that is especially loose in formal organization.

Furthermore, this example features a situation that is somewhat akin to what we observed in example 3. If we recognize an elided PAC at m. 18, as Ed shows in his annotations of example 5, then my proposed evaded cadence at m. 23 and subsequent "one more time" technique would see the music backing up to the "beginning" of the new theme. This view is reasonable in light of the manifest sense that a functional initiation takes place at $\mathrm{m}$. 18, as expressed by the appearance of a new two-bar group supported by a firm root-position tonic prolongation. On the contrary, if we believe that $\mathrm{m}$. 18 brings instead an evaded cadence, such that the ongoing thematic process has not yet achieved its goal, then the "one more-time" technique at $\mathrm{m}$. 23 would represent a backing up to a medial position (m. 18) within a thematic process begun at m. 9 , thus conforming more to the norms of classical form.

To conclude my discussion of this essay, I want to ask whether a distinct "sonatina form" emerges from Ed's analyses. This is not a topic that he addresses head on, but by showing that these works lie within a continuum of formal possibilities between a highly compressed minuet form at one end and a full-fledged sonata form at the other, he suggests that no single "sonatina form" can be identified as such and that there would seem to be a wide range of possible expositional plans that are usable when composers want to write a piece entitled "sonatina." I have argued elsewhere that a theory of form should focus more on formal function (the distribution of thematic and phrase functions within a movement) than on formal type (such as sonata form versus sonatina form). ${ }^{4}$ I believe that Ed has followed in this spirit by showing how cleverly Clementi manipulates formal functionality, even in these deliberately miniature compositions.

3 Schmalfeldt, "Cadential Processes," 20-21, discusses how the use of the "one more time" technique can help clarify moments that are cadentially ambiguous.

4 "What are Formal Functions?" in Musical Forms, Form \& Formenlehre, 31-34. 


\section{Mark Richards}

Mark Richards' thought-provoking paper confronts a number of thorny issues associated with the classical cadence, a topic that is already fraught with innumerable difficulties, and his proposals for dealing with some of the more problematic cases that arise now and then are imaginative. With respect, however, I find myself having to take issue with some of his novel concepts. It is possible, of course, that I have been so long immersed in these matters that my thinking has become even more rigid than usual. But if the following comments tend to challenge many of Mark's propositions, perhaps they will stimulate further dialogue concerning the analysis and experience of closure in tonal music.

I will address the three subtopics of Mark's paper in order, beginning with the extent to which melody and texture constitute significant criteria for our perceiving the onset of cadential function. First, let me reassert a distinction that I have promoted throughout my writings-that grouping structure and formal functionality are different musical phenomena originating in different musical processes. To be sure, a given group, say a four-bar phrase, may have a unique formal function. But often enough a group may fuse together more than one function, or a single function may be expressed by multiple groups. In my view, melody and texture are important for defining grouping structure, and changes in these parameters typically create the boundaries of formal units. But do such changes also decisively effect formal functionality? To this question, I have consistently argued "No," finding instead that harmony and tonality are the primary criteria for establishing form-functional differentiation. Thus with respect to cadence, I hold that a change in grouping per se is insufficient to articulate the onset of cadential function unless that group actually contains a cadential harmonic progression. To be sure, grouping structure can sometimes clarify ambiguous situations, especially where a given tonic harmony can be heard as participating in either a prolongational or cadential role. In Mark's example 2, for instance, I concur: the I ${ }^{6}$ harmony of m. 6 can be heard as belonging to the continuation function, and the cadential function can be understood as arising in the next bar, with the change of grouping effected by melody and texture. But the situation is perhaps different in example 5, where m. 96 clearly marks the beginning of a new group. Although this group indeed ultimately brings about cadential function, is that function perceived from the very beginning of the group? For me, the harmonic motion from I to $\mathrm{I}^{6}$ continues the tonic prolongation from the prior group, and only when the $\mathrm{I}^{6}$ moves to the pre-dominant $\mathrm{II}_{5}^{6}$ are we fairly certain that a cadential progression is in the making. Here, then, is a case where I would recognize a fusion of continuation and cadential functions occurring within a single group (mm. 96-101), a situation that is quite common in sentential formations.

Mark's example 4 brings a particularly interesting case where being sensitive to the harmonic details, and the bass line that supports those details, helps to clarify the formal functions of the theme. 5 Focusing largely on grouping

5 I discuss the importance of attending to the bass line of classical themes in my essay "Schoenberg's 'Second Melody,' Or, 'Meyer-ed' in the Bass," in Communication in Eighteenth-Century Music, 
structure, Mark wants to hear the progression $\mathrm{V}_{5}^{6}-\mathrm{I}$ at $\mathrm{m} .9$ as initiating the cadential function. I understand the harmonic situation to be quite different, noting that $\mathrm{I}^{6}$ is prolonged throughout $\mathrm{mm} .5^{-8}$ to such an extent that we might even wonder whether an expanded cadential progression (ECP) were in the making. But by decisively turning back to a root-position I, via the $\mathrm{V}_{5}^{6}$ on the downbeat of m. 9, Mozart seems to "abandon" the potential ECP. ${ }^{6}$ Indeed such a situation - where the onset of a cadential progression is signalled by a return to a root-position tonic following the appearance of a prominent firstinversion tonic-would be very uncharacteristic. A shift of the bass line from $\hat{3}$ down to $\hat{i}$ would strongly counteract the more normal tendency of the bass to ascend (to the pre-dominant) in cadential situations. Thus I hear the return to root-position tonic in $\mathrm{m} .9$ as either the final stage of a broad prolongation (begun at the very start of theme) or else as a cadential abandonment (as described above), such that the cadence begins with the pre-dominant $\mathrm{II}^{6}$ in the second half of the bar. That a new "group" begins on the downbeat of $\mathrm{m} .9$ is, for me, an insufficient rationale for locating the onset of cadential function.

Let us now turn to Mark's second topic, his notion of "closural function." Once again I want to emphasize a distinction essential to my understanding of classical harmony and form-the fundamental difference between prolongational and cadential progressions, to which I have already alluded. The cases that Mark wants to identify as exhibiting closural function involve tonics that, in my opinion, emerge out of prolongational harmonic contexts-progressions that sustain a given harmony in time through the use of subordinate harmonies (e.g., I-V $\mathrm{V}^{6}-\mathrm{I}$ ). Such progressions are not, to my ears, "cadence-like"; they do not result in any genuine confirmation of a tonal centre. Thus in example 9, I hear the tonic of m. 4 as completing a prolongation, and so I do not experience any sense of thematic closure. Indeed, such a progression is never used by classical composers to complete a full theme (of minimally eight bars). To be sure, when the similar situation returns at m. 8 and is sustained through $\mathrm{m}$. 10, we might feel more a sense of ending in response to the final silence. But instead I hear a clear continuation function, as marked by the repeated one-bar groupings, the accelerated surface rhythms, and most importantly, the tonic prolongation. The silence, for me, is one of Haydn's commonly occurring "mid-phrase" pauses, which so often precedes the cadence that closes the theme. And if we append a real cadence to the passage in question, as shown in my example 1, we can readily hear a case of genuine thematic closure. That Haydn omits such a cadence and leaves the theme open-ended is, as Mark points out, part and parcel of this composer's characteristic wit.

That Mark's "closural functions" are more accurately conceived as subthematic (that is, taking place somewhere in the middle of a full thematic process, not at its end) is especially observable in connection with his example 7 . Here, the "sense of ending" associated with the completion of the pedal within $\mathrm{mm}$. 38-44 pertains exclusively to the closure of an ongoing phrase, one that 


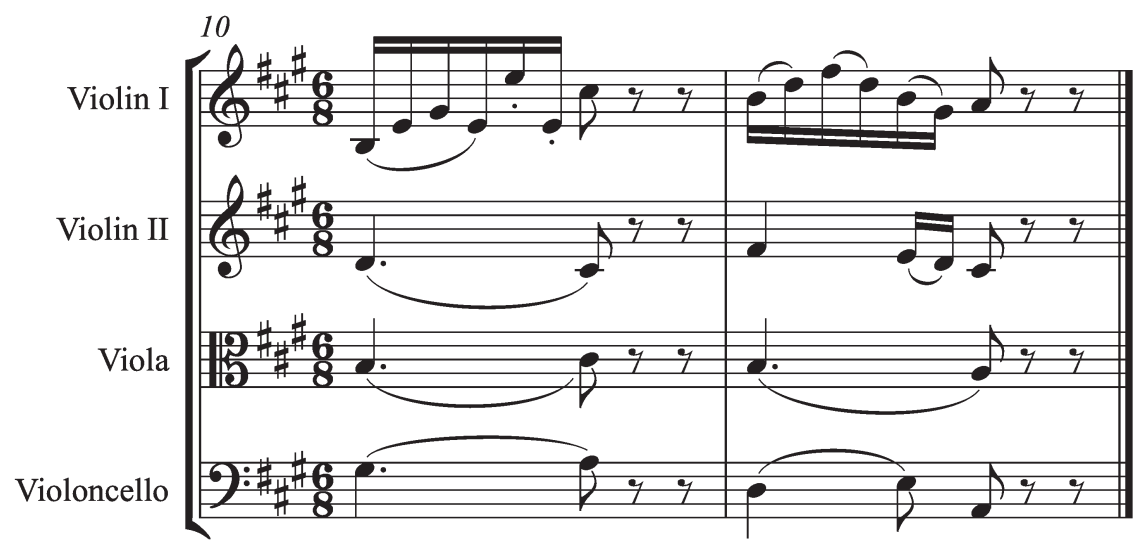

Figure 1.

is internal to the complete thematic process-the transition of the exposition, the real ending of which occurs much later at m. 58 (to be sure, in the form of the half-cadential deviation I term "dominant arrival"). ${ }^{7}$ Given that the situations Mark describes as "closural functions" are never used to end complete themes, I believe that they are more akin to non-cadential phrase endings than to actual cadences.

Finally, let us consider Mark's third topic, the idea of a "separated cadence." As his example 11 makes clear, the two principal voices of a cadence often achieve melodic closure at different points in time. In that particular sense, the idea of a separated cadence has some validity, at least as a term to characterize the lack of coordination between the parts. But a number of questions nevertheless arise. Do we hear two separate moments of cadential arrival? Do we experience a partial arrival when the bass resolves and then a more complete arrival when melodic closure follows thereafter? Or, as becomes clearer in his discussion of example 14, do we hear the stretch of time between one melodic closure and the other as an arrival that has been "spread out"?

My own view of the matter is that cadential arrival occurs at one specific point in time, and that arrival is articulated not necessarily by the closure of any particular voice, but rather by the moment when we perceive the onset of the final harmony of the cadential progression. Inasmuch as I hear cadential arrival articulated by harmony, not by melody, there can be only one moment when a harmonic change takes place. So I do not perceive two different timepoints articulating two different cadential arrivals, as Mark suggests.

Moreover, if we compare example 14 to example 13a, it would seem that Mark regards the twelve-bar time span between mm. 75-87 of the Tempest as functionally equivalent, say, to the quarter-note time span between the bass

7 It is interesting to observe that although dominant arrivals appear commonly enough to close loosely organized thematic processes (such as a transition or the core of a development), the analogous notion of "tonic arrival" seems never to be used by the classical composers. Rather, thematic closure on tonic harmony is achieved in this style only by genuine authentic cadences. 
and melodic resolutions of the Mozart sonata. In the latter, that time span is a brief extension of the final tonic harmony of the cadence. But do we really hear the twelve bars of the Tempest as functionally equivalent to the single bar of tonic in the Mozart? Moreover, what are we to make of the formal situation during this twelve-bar span? Do we merely hear a functional hiatus? This view would perhaps be closer to what Rothstein understands with his notion of interpolation. But both Schmalfeldt and I see these measures expressing a distinct formal function: she regards the stretch of time as a series of evaded cadences; I see it as a post-cadential closing section. For me, then, the idea of a separated cadence is intriguing but problematic in a number of respects.

Though I have challenged many of the positions developed in Mark's study, I nonetheless want to conclude by congratulating him for grappling with some difficult cases involving cadence. If I am not entirely convinced by his proposals, the questions that he poses and the answers that he offers stimulate us to continue probing the complexities and richness of closure in music of the classical style.

\section{Carl Wiens}

In this engaging and informative study, Carl Wiens considers some complex aspects of expositional structure and, in so doing, raises important points about theory and methodology. In particular, the question of whether a given passage represents a two-part transition or a two-part subordinate theme forces us to come to grips with the fundamental criteria used to differentiate these thematic functions. In general, I find that Carl has discussed their potential confusion with clarity and, for the most part, I find his conclusions to be sound and well-grounded in accurate analyses. Since the Sonata in F major, op. 10, no. 2, is the somewhat easier piece to interpret, I will begin my discussion with that movement, turning then to the greater complexities presented by the Sonata in C major, op. 2, no. 3, a movement that continues to give me analytical headaches every time I examine it anew.

But first, a general point of theory to help guide our considerations. Carl offers some useful criteria when discussing how to differentiate between a twopart transition and a two-part subordinate theme within an exposition, but he does not sufficiently highlight what is perhaps the most decisive criterion of all-the fundamental conflict of tonalities lying at the heart of a sonata exposition. For it is a fundamental postulate of classical form that the thematic function of transition must begin in the home key, whereas the function of subordinate theme must begin in the subordinate key. And the idea that the initiating unit of the transition must reside in the home key extends, in the case of a two-part structure, to both of its parts. ${ }^{8}$

With these tonal distinctions in mind, we can re-examine op. 10, no. 2, and observe that the unit beginning at $\mathrm{m}$. 19 resides entirely in $\mathrm{C}$ major, the subordinate key. This fact alone should encourage us to hear this moment as the

8 The second part of a two-part transition frequently may begin, however, in a non-tonic region of the home key, especially VI (see Classical Form, Ex. 9.4, mm. 33-34). 
beginning of the subordinate theme. To be sure, the lack of an emphatic dominant of the new key, to help set up its tonic at m. 19, might be troubling to some listeners. But the E-major sonority in the two previous bars can clearly be heard as V of VI in C major, a standard "substitute" for the real dominant. Of course, the new-key dominant is then given marked emphasis later in $\mathrm{mm}$. 30-37, which prompts Carl (and many others) to regard this harmony as the ending dominant of the transition. But then, can we identify a good "beginning" for the subordinate theme? Not really. The new phrase at m. 38, which leads to the IAC, exhibits essential features of a continuation (fragmentation into one-bar units, a marked acceleration of the harmonic rhythm), and so this passage sounds very much like a resumption of the thematic processes initiated earlier. In fact, the lack of a substantial continuation following the large-scale presentation in $\mathrm{mm}$. 19-26 surely helps motivate the reappearance of continuation function at $\mathrm{m}$. 38, which, following the weak cadence at $\mathrm{m} .41$, is repeated and highly extended. ${ }^{9}$ In short, I see no reason to identify a twopart transition in this exposition and find entirely convincing the idea that the subordinate theme begins as early as $\mathrm{m}$. 19, despite the extremely short transition that precedes this moment. ${ }^{10}$

With the C-major sonata, however, the situation is more complex, for the passage in question at $\mathrm{m} .27$ begins in $\mathrm{G}$ minor. Is this already the subordinate key? In principle, yes. We know from the previous Piano Sonata in A major, op. 2, no. 2, that Beethoven can begin a subordinate theme directly in the minor mode of the new key (in this case, E minor). Moreover, this theme begins immediately with a prominent model-sequence pattern that is highly destabilizing, a technique also found in our C-major sonata. In other words, there are clear grounds for identifying a two-part subordinate theme in op. 2 , no. $3 .{ }^{11}$

But a significant difference between the two op. 2 sonatas is how the immediately preceding transitions close. In the A-major sonata, the music has already modulated to the new key, ending there with its dominant. So we are fully prepared to hear E minor as a subordinate-key tonic. In the C-major sonata, on the contrary, the music preceding the passage in $\mathrm{G}$ minor still resides fully in the home key, and we may not be quite as ready to accept G minor as the subordinate key. As well, the melodic material presented later on at $\mathrm{m} .47$ sounds very much like a new beginning, one that could easily be construed

9 The continuation phrase of the subordinate theme's first part, mm. 27-30, is unusually short, consisting only of a partial restatement of the basic idea before leading all to quickly into the HC at m. 30. The only substantial characteristic of continuation function present in this passage is an acceleration in the rate of harmonic change.

10 Whether or not the subordinate theme of this F-major sonata is really in two parts remains open to further discussion. In Classical Form (117), I employ the term "two-part subordinate theme" only in those cases where, following an internal half cadence and standing on the dominant, a new initiating function appears to signal the onset of the second part. Thus the situation obtaining in op. 10, no. 2, would, technically speaking, not be a two-part transition, since the material that follows the standing on the dominant is continuational, and thus seems to resume an ongoing process that was temporarily interrupted by the half cadence.

11 Here the term two-part subordinate theme is fully justified in that the new material at m. 47 has, as Carl points out, strong initiatory qualities and thus does not seem like a resumption of an ongoing thematic process (such as we discussed in connection with $\mathrm{mm}$. $38 \mathrm{ff}$. in the F-major sonata). 
as the start of the subordinate theme. In other words, the case for a two-part transition in op. 2, no. 3 , is entirely plausible. To be honest, I am constantly wavering in my own opinion on how to analyze this passage. It seems that Beethoven has found the perfect way of creating a true formal ambiguity here.

Let us turn now to the question of whether the recapitulations can help solve the difficulties presented by these expositions. We should recall that whereas we label the principal thematic regions of the recapitulation using the same terms as those in the exposition, we must also acknowledge the major functional differences served by the recapitulation's main theme, transition, and subordinate theme. Most importantly, the fact that this large-scale section of sonata form remains entirely in the home key means that tonality can no longer help us distinguish a subordinate theme from a transition, as was the case with the exposition. Indeed the recapitulation's transition acquires an entirely new function: there is no need for it to destabilize the home key in order for a new "sharp-side" subordinate key to emerge. Rather, the transition provides harmonic contrast with an emphasis on "flat-side" regions so that the home-key tonic beginning the recapitulation's subordinate theme can sound fresh again.

How do these considerations affect our two sonatas? In op. 10, no. 2, Carl has already discussed how the music serving as the transition from the exposition is eliminated in the recapitulation, ${ }^{12}$ and I further agree with him that the following passage, which I identified as the opening of the subordinate theme of the exposition, now takes on a transitional function in the recapitulation. In particular, we should note that the change in harmonic orientation from m. 153 onward brings a marked emphasis on flat-side regions. Such an adjustment is more typical of a recapitulation's transition than of its subordinate theme, which tends to remain faithful to the harmonic structure given in the exposition. In other words, similar music can be assigned two different formal functions: subordinate-theme function in the exposition; transition function in the recapitulation. Likewise in the op. 2, no. 3, sonata, I agree with Carl: the balance tips more toward the side of finding a two-part subordinate theme in the recapitulation. ${ }^{13}$

But I depart from Carl's suggestion that our knowledge of how a passage may end up functioning in the recapitulation should then be transferred back and influence how we hear similar music in the earlier exposition. Since we

12 In addition to the many fine reasons that Carl proposes for Beethoven's choice to eliminate the exposition's transition from the recapitulation, I would further point out that the tonal adjustment that would normally take place in this transition would have had it end with dominant harmony of the home-key submediant (V/VI), exactly that harmony that was emphasized at the end of the development (mm. 113-16) just prior to the false recapitulation. The joke that was played in the exposition, where the V/VI (in the new key) does not resolve as expected, cannot effectively be repeated in the recapitulation when, just a bit earlier, the same harmony had resolved correctly to create the false recapitulation.

13 It is very striking that the music of the exposition beginning in G minor (mm. 27-46) returns in the recapitulation ( $\mathrm{mm} .161-78)$ without any phrase-structural or harmonic changes (other than being transposed back into the home key). This lack of any formal alterations strongly suggests that the music is serving more a subordinate-theme function than a transitional one. 
should not automatically assume that comparable music fulfills a comparable function (although it often does do so), we should allow each section to define its own compositional logic independently. The ambiguities of formal expression in the exposition of op. 2, no. 3 are not, to my hearing, resolved by my later knowledge that a comparable passage projects its own formal functions less ambiguously in the recapitulation. When engaging such long-term relationships within a movement, I would prefer instead to allow the music in its own contexts to define its own formal functionality. Indeed we must sometimes be content to live with some formal ambiguities without necessarily insisting upon a final-state resolution of them.

I hope that my remarks have helped to clarify the arguments raised in the valuable analytical work presented here by Professors Jurkowski, Richards, and Wiens, and that this volume will promote further discussions on these important matters of theory, analysis, and compositional technique.

\section{WORKs Cited}

Caplin, William E. 1998. Classical Form: A Theory of Formal Functions for the Instrumental Music of Haydn, Mozart, and Beethoven. Oxford: Oxford University Press.

. 2008. 'Schoenberg's 'Second Melody,' or, 'Meyer-ed' in the Bass." In Communication in Eighteenth-Century Music, ed. Danuta Mirka and Kofi Agawu, 160-188 (Cambridge: Cambridge University Press).

. 2009. "What Are Formal Functions?" In Music, Forms \& Formenlehre: Three Methodological Reflections (by William E. Caplin, James Hepokoski, and James Webster), edited by Pieter Bergé, 21-40. Leuven: Leuven University Press.

Hepokoski, James, and Warren Darcy. 2006. Elements of Sonata Theory: Norms, Types, and Deformations in the Late-Eighteenth-Century Sonata. Oxford: Oxford University Press.

Schmalfeld, Janet. 1992. "Cadential Processes: The Evaded Cadence and the 'One More Time' Technique.” Journal of Musicological Research 12:1-52. 